\title{
Incidence Trends of Dermatophytoses Isolated in Children
}

\author{
Su Jung Kim ${ }^{1}$, Yong Joon Bang ${ }^{2}$ \\ ${ }^{1}$ Department of Biomedical Laboratory Science, Daegu Health College, Daegu, Korea \\ ${ }^{2}$ Catholic Skin Clinic, Dermatology, Daegu, Korea
}

\section{소아에서 분리된 피부진균증의 발생경향}

\author{
김수정 ${ }^{1}$, 방용준 $^{2}$ \\ ${ }^{1}$ 대구보건대학교 임상병리과, ${ }^{2}$ 가톨릭피부과의원
}

\begin{abstract}
From January 2 to December 30, 2017, out of 691 children diagnosed with dermatophytoses infection, 179 children had infections caused by Trichophyton among the total 13,093 patients who visited the Dermatology department. According to a survey, the patients included 317 adolescents, 203 elementary school age children, and 171 infants. In seasonal variation, the diagnosis was higher in summer (195 cases, 28\%) and winter (191, 28\%) and comparatively lower in spring (165, $24 \%$ ) and autumn (140, 20\%). The infection among the patients was caused by, from maximum to minimum, T. pedis $(351,51 \%)$, T. corporis $(91,13 \%)$, and T. unguinum $(77,11 \%)$. In all age groups, the highest number of patients were infected with T. pedis. After T. pedis, in descending order, the infection was caused by T. corporis, T. unguinum, T. manus and Tinea capitis in the infants and elementary school age children and by T. corporis, T. unguinum and T. cruris in adolescents. Among infections caused by Trichophyton, T. rubrum was the highest isolated causative agent. This data analysis confirmed the distribution of dermatophytoses and the different species according to paediatric age and will aid the study of paediatric dermatomycosis through continuous research.
\end{abstract}

Key words: Dermatophytoses, Tinea pedis, Trichophyton rubrum

This is an Open Access article distributed under the terms of the Creative Commons Attribution Non-Commercial License (http://creativecommons.org/licenses/by-nc/4.0) which permits unrestricted non-commercial use, distribution, and reproduction in any medium, provided the original work is properly cited.

Copyright @ 2018 The Korean Society for Clinical Laboratory Science. All rights reserved.
Corresponding author: Su Jung Kim Department of Biomedical Laboratory Science, Daegu Health College, Youngsong-ro, Daegu 41453, Korea

Tel: 82-53-320-1303

Fax: 82-53-320-1450

E-mail: sjkim4238@hanmail.net

Received: October 20, 2018

Revised $1^{\text {st: }}$ November 2, 2018

Revised $2^{\text {nd }}:$ November 7, 2018

Accepted: November 8, 2018

\section{서 론}

피부진균증은 지리적, 시대적, 경제적 조건 및 생활환경 등에 따라 발생 빈도의 차이를 나타내는 진균으로인한 감염성 질환 이며 감염부위로는 피부각질층, 체모, 손발톱, 두피 등이다 [1-3]. 국내 피부진균증에 대한 연구는 Suh 등[4]이 전국규모의 역학적 및 균학적 연구를 시작하였으며 그 다음으로 Won 등[5] 이 1976 1985년 사이의 10 년간의 피부진균증의 임상 및 균학 적 연구를 실시하였고 Lee 등[1]이 1992 2000년, Moon 등[2] 이 2001 2010년에 피부진균증을 전국규모로 연구를 수행하 였다. 이런 조사로 인해 피부 진균들이 부위와 질환에 따라 분리
율에 차이가 있음을 확인하였으며 이는 우리나라의 경제성장과 사회변화, 생활 환경의 변화가 피부진균의 패턴에도 많은 영향 을 준 것으로 조사되었다 $[1,2,4,5]$. 국가 경제 및 생활수준과 환경의 변화는 성인뿐만 아니라 성장하는 소아청소년에게도 영 향을 줄 것으로 생각되며 면역력이 낮은 소아청소년의 세부적 발단단계에 따른 조사는 Hyun 등[6]이 1976년에서 2005년까 지 대구 지역의 소아에서 분리된 피부진균의 임상과 균학적 관 찰에 대한 연구를 수행한 것이 유일하였고 그 이외에는 단일 피 부진균증에 대한 균학적 보고만 조사되었으며 가장 많은 연구 가 진행된 단일 균종으로는 동물친화성인 M. canis가 애완동물 의 사육으로 인해 꾸준히 증가추세이다[7-12]. 이런 이유로 본 
연구진은 2017년 대구소재의 가톨릭 피부과의원에서 소아청 소년을 대상으로 분리된 피부진균증환자 자료를 의뢰 받아 분 리분포 및 분리균종을 분석하여 보고하고자 한다.

\section{재료 및 방법}

\section{1. 연구 대상}

2017년 1월 2일부터 2017년 12월 30일까지 대구 지역내 가 톨릭 피부과의원을 내원한 소아청소년환자 중 $20 \% \mathrm{KOH}$ 검사 및 진균배양 검사를 수행하였고 소아 피부진균증으로 진단된 환자 자료를 의뢰 받아 분석하였으며 본 연구는 대구보건대학 교 기관생명윤리위원회의 심의를 받아 승인 후 연구를 수행하 였다. 채취절차와 관련하여 채취 시 부작용 및 채취과정을 설명 하여 동의를 얻어 진행하였다. 소아청소년환자검체로부터 진 균의 분리분포에 대해 조사하였다.

\section{2. 진균학적 검사}

피부진균증의 진단은 $\mathrm{KOH}$ 검사로 확인하며 검사방법은 질 환부위를 70\% 알코올로 소독 후 검체를 채취하여 $20 \% \mathrm{KOH}$ 용

Table 1. Gender ratio of patients with dermatophytoses

\begin{tabular}{lcc}
\hline \multirow{2}{*}{ Disease } & \multicolumn{2}{c}{ No. of patient } \\
\cline { 2 - 3 } & Male & Female \\
\hline Tinea capitis & 20 & 19 \\
Tinea facial & 12 & 10 \\
Tinea corporis & 56 & 35 \\
Tinea cruris & 46 & 9 \\
Tinea manus & 17 & 12 \\
Tinea pedis & 217 & 136 \\
Tinea unguium & 48 & 29 \\
Other & 7 & 18 \\
Total No. & 423 & 268 \\
\hline
\end{tabular}

액을 처리한 후 균사를 광학현미경으로 관찰하였다. 백선균 배 양과 동정을 위해 potato dextrose agar/corn meal tween 80 배지에 접종한 후 $25^{\circ} \mathrm{C}$ 에서 3 4주간 배양한다. 배양된 집락을 육안적 관찰한 후 lactophenol cotton blue로 염색하여 현미경 으로 균사체를 관찰하여 원인균을 최종 동정하였다[13-15].

\section{3. 통계 처리}

SPSS version 21.0 (SPSS version 18.0, SPSS Inc., Chicago, IL, USA)를 이용하여 기술통계처리하여 빈도분석하였다.

\section{결 과}

\section{1. 성별에 따른 질환별 분포}

$\mathrm{LPCB}$ 로 염색하여 현미경으로 관찰하여 피부진균을 동정확 인 결과 전체 소아청소년환자 691명 중 남성은 423명으로 $61 \%$ 이며 여성은 268 명으로 $39 \%$ 로 분포하였다. 가장 분포율이 높 은 부위로는 남성과 여성 모두 족부백선에서 217명(51\%), 136 명(51\%)으로 분포하였다. 피부진균증이 아닌 것을 묶어 나머지 로 분류하였다(Table 1).

\section{2. 연령별 분포}

연령군의 분류는 소아과학에서 기술한 기준으로 분류하였으 며 이는 신체적 변화, 사회적 변화, 그리고 노출되는 외부환경의 작용을 고려하여 영유아기(0 6세), 학령기(7 12세), 그리고 사춘기(13 18세)로 나누어 조사하였다[16]. 조사결과 신체변

Table 2. Age distribution of children patients with dermatophytoses

\begin{tabular}{ccccc}
\hline Age & $0 \sim 6 \mathrm{yr}$ & $7 \sim 12 \mathrm{yr}$ & $13 \sim 18 \mathrm{yr}$ & Total \\
\hline No.of patient & 171 & 203 & 317 & 691 \\
Rate (\%) & $25 \%$ & $29 \%$ & $46 \%$ & $100 \%$ \\
\hline
\end{tabular}

Table 3. Seasonal distribution of tinea

\begin{tabular}{|c|c|c|c|c|c|}
\hline \multirow{2}{*}{ Disease } & \multicolumn{5}{|c|}{ Month } \\
\hline & Spring (Mar May) & Summer (Jun Aug) & Autumn (Sep Nov) & Winter (Dec Feb) & Total No. \\
\hline Tinea capitis & 8 & 7 & 13 & 11 & 39 \\
\hline Tinea facial & 6 & 4 & 6 & 6 & 22 \\
\hline Tinea corporis & 27 & 28 & 18 & 18 & 91 \\
\hline Tinea cruris & 8 & 20 & 16 & 11 & 55 \\
\hline Tinea manus & 5 & 4 & 6 & 14 & 29 \\
\hline Tinea pedis & 91 & 99 & 62 & 102 & 353 \\
\hline Tinea unguium & 18 & 27 & 9 & 23 & 77 \\
\hline Other & 2 & 6 & 10 & 6 & 24 \\
\hline Total No. & 165 & 195 & 140 & 191 & 691 \\
\hline Rate (\%) & $24 \%$ & $28 \%$ & $20 \%$ & $28 \%$ & $100 \%$ \\
\hline
\end{tabular}


화가 가장 많은 시기인 사춘기 $(317$ 명, $46 \%)$ 에서 피부진균증이 높게 나타났고 다음으로 학령기(203명, 29\%)와 영유아기(171 명, 25\%)의 순서로 나타났다(Table 2).

\section{3. 계절별에 따른 질환별 분포}

사계절로 나누어 조사한 결과 피부진균증은 여름(195명, $28 \%)$ 과 겨울(191명, 28\%)이 높게 분리되었고 봄(165명, 24\%) 과 가을 $(140$ 명, $20 \%)$ 의 순으로 분리되었다. 봄에는 족부백선의 분리율이 가장 높고 몸백선, 조갑백선의 순서로 분리되었다. 여 름은 족부백선, 몸, 조갑, 그리고 사타구니백선으로 분리되었다. 가을은 족부백선이 가장 분리율이 높고 몸, 사타구니, 그리고 두 부백선으로 분리되었다. 겨울은 족부백선이 가장 높게 분리되었 고 조갑백선과 몸백선의 순으로 분리되었다. 사계절 모두 족부백 선의 분리비율이 높게 나타났으며 사계절 중 겨울(102명), 여름 (99명), 봄(91명), 그리고 가을(62명)의순으로 분리되었다. 피부 진균증이 아닌 것을 묶어 나머지로 분류하였다 (Table 3).

\section{4. 부위별 분포}

부위별로는 족부백선(353명, $51 \%)$ 로 가장 많았으며 다음 순 으로는 몸(91명, $13 \%$ ), 조갑(77명, $11 \%)$, 사타구니(55명, $8 \%)$,

Table 4. Distribution of clinical types of tinea

\begin{tabular}{lcc}
\hline \multicolumn{1}{c}{ Disease } & No. of patient & Rate (\%) \\
\hline Tinea capitis & 39 & $6 \%$ \\
Tinea facial & 22 & $3 \%$ \\
Tinea corporis & 91 & $13 \%$ \\
Tinea cruris & 55 & $8 \%$ \\
Tinea manus & 29 & $4 \%$ \\
Tinea pedis & 353 & $51 \%$ \\
Tinea unguium & 77 & $11 \%$ \\
Other & 25 & $4 \%$ \\
Total No. & 691 & $100 \%$ \\
\hline
\end{tabular}

Table 5. Age distribution of clinical types of tinea

\begin{tabular}{lccc}
\hline \multirow{2}{*}{ Disease } & \multicolumn{3}{c}{ Age } \\
\cline { 2 - 4 } & $0 \sim 6 \mathrm{yr}$ & $7 \sim 12 \mathrm{yr}$ & $13 \sim 18 \mathrm{yr}$ \\
\hline Tinea capitis & 22 & 10 & 7 \\
Tinea facial & 7 & 8 & 7 \\
Tinea corporis & 26 & 22 & 43 \\
Tinea cruris & 8 & 8 & 39 \\
Tinea manus & 9 & 11 & 9 \\
Tinea pedis & 68 & 122 & 163 \\
Tinea unguium & 22 & 14 & 41 \\
Other & 9 & 8 & 8 \\
Total No. & 171 & 203 & 317 \\
\hline
\end{tabular}

두부(39명, $6 \%$ ), 수부(29명, $4 \%$ ), 그리고 얼굴백선(22명, $3 \%)$ 의 순으로 분리되었으며 피부진균증이 아닌 것을 묶어 나머지 로 분류하였다(Table 4).

\section{5. 연령군에 따른 질환별 분포}

유아기(0 6세)에서는 족부백선이 가장 많이 분리되었고 몸, 조갑, 그리고 두부백선에서 주로 분리되었다. 학령기(7 12세) 는 족부백선이 가장 많이 분리되었고 몸, 조갑, 수부, 그리고 두 부백선의 순으로 분리되었다. 사춘기(13 18세)에서는 족부백 선이 가장 많이 분리되었고 몸, 조갑, 그리고 사타구니백선으로 분리되었다. 피부진균증이 아닌 것을 묶어 나머지로 분류하였 다(Table 5).

\section{6. 균종별 분포}

$20 \% \mathrm{KOH}$ 직접도말 검사와 potato dextrose agar/corn meal tween 80 배지에서의 성상 및 $\mathrm{LPCB}$ 로 염색한 결과로 백 선균의 분리율은 179주로 25.9\%이며 나머지 Candida albicans, 배양음성, 오염균으로 분류되었다. 분리된 백선균중 가장 많은 원인균은 Trichophyton rubrum, 다음 순으로는 Microsporum canis, Trichophyton mentagrophytes, Epidermophyton floccosum, Trichophyton. verrucosum Trichophyton. tonsurans, Microsporum gypseum으로 분리 되었다. 효모균과 비배양균을 합쳐서 나머지로 분류하였다 (Table 6).

\section{고 찰}

피부진균증은 피부, 조갑, 체모, 두부, 족부, 사타구니, 그리 고 몸 전체에 다양한 진균의 감염으로 나타나는 감염성 질환이

Table 6. Distribution of causative agent of tinea

\begin{tabular}{lcc}
\hline \multicolumn{1}{c}{ Dermatophyte } & Number & Rate (\%) \\
\hline T. rubrum & 143 & $21 \%$ \\
M. canis & 23 & $3 \%$ \\
T. mentagrophytes & 4 & $1 \%$ \\
E. floccosum & 2 & $0 \%$ \\
T. verrucosum & 1 & $0 \%$ \\
T. tonsurans & 1 & $0 \%$ \\
M. gypsenm & 5 & $1 \%$ \\
T. ferrugineum & 0 & $0 \%$ \\
T. violaceum & 0 & $0 \%$ \\
Other & 512 & $74 \%$ \\
Total & 691 & $100 \%$ \\
\hline Abbreviations: $\quad$ T, & Trichophyton; & E, Epidermophyton; $\quad M$ \\
Microsporum. & &
\end{tabular}


다. 감염의 원인은 숙주의 위생 및 건강상태, 그리고 주변 환경적 요인 등으로 인체에 유발된다[17-19]. 최근 급격한 경제성장과 생활환경의 변화를 가져왔기에 피부진균증에 따른 균종의 분포 도 변화하고 있다[1]. 과거 1991 2000년도에는 남녀 발생빈도 가 1.3:1로 남성의 피부진균증발생율이 높았고, 계절로는 여름 이 높고 봄, 가을, 겨울의 순으로 분리되었다. 부위별로는 족부백 선이 가장 많고 다음으로 조갑백선이었다. 원인균종으로는 $T$. rubrum의 분리가 높았고 다음으로 T. mentagrophytes $M$. canis 가 분리되었다[2]. 이어진 연구로는 2001년에서 2010년 에는 피부진균증의 남녀 발생빈도가 $1.2: 1$ 로 남성의 발생율이 약 간 높았고, 계절로는 여름이 높고 가을, 봄, 겨울의 순으로 분리되 었다. 부위별로는 족부백선이 가장 많고 다음으로 조갑백선이었 다. 원인균종으로는 T. rubrum의 분리가 가장 높았고 다음으로 M. canis, T. mentagrophytes가 분리되었다[1]. 시대별로 피부 진균증은 남녀차이, 계절, 감염부위별, 그리고 원인균종별로 차 이를 보이고 있었다. 이런 조사결사는 전연령층을 대상으로 하였 기에 인체 변화가 가장 많은 소아청소년의 피부진균증관련 자료 를 파악하기에는 부족하였다. Hyun 등은 소아를 대상으로 1976 년부터 2005년까지 영유아기, 학령기, 사춘기로 나누어 임상적 관찰과 진균학적 관찰을 수행하였다[6]. 남녀 발생빈도는 1.5:1 로 남성의 비율이 다소 높았고 계절별로는 여름(36.2\%)이 가장 높고 겨울(25.6\%), 가을(19.3\%), 그리고 봄(18.9\%)의 순으로 분 리되었다. 부위별로는 족부백선이 $25.6 \%$ 로 가장 많았고 사타구 니백선, 두부백선, 몸백선, 조갑백선, 얼굴백선으로 나타났다. 연 령별로는 사춘기가 $44.7 \%$, 학령기는 $24.6 \%$, 영유아기는 $30.7 \%$ 로 분포하였다. 원인균종으로는 T. rubrum의 분리율이 $53.7 \%$ 로 가장 높았고 다음으로 M. canis(30.6\%), T. mentagrophytes (9.6\%)의 순으로 분리되었다[6]. 2005년 이후에는 소아청소년 을 대상으로 전반적인 연구는 없었다. 그러나 고도의 산업화로 인해 가족구성에도 많은 변화를 가져왔으며 가족의 빈자리를 반 려동물이 새롭게 자리잡게 되었고 이로 인해 동물친화성 피부사 상균의 감염이 증가하였으며 다양한 애완동물로 인해 $T$. mentagrophytes, 개와 고양이로 인해 M. canis, 소의 접촉으로 T. verrucosum에 대한 단일 균종분리를 보고하였다[20-24].

이에 본 연구진은 2017년 1월부터 12월 사이 피부과를 내원 한 소아청소년환자를 대상으로 남녀별, 연령별, 계절별, 감염부 위별, 질환별 분포에 대해 조사하였다. 분석 결과 성별의 차이는 남녀비가 1.57:1의 비율로 남성이 조금 높았으며 이는 Hyun 등 의 조사와 거의 유사한 분포를 보였으며 이는 소아청소년의 발 달에서 남성이 신체적, 의복의 구조에 따라 감염에도 영향을 미 친다고 생각된다[6].
세부연령에 따른 피부진균증의 분포는 외부환경과 신체발달 이 다양한 시기인 사춘기가 $46 \%$ 로 높았고 학령기(29\%)와 영유 아기(25\%)는 비슷하게 분포하였다. Hyun 등의 조사와 본 연구 를 비교시 사춘기와 학령기는 비슷하게 분포하였으나, 영유아 기는 다소 낮게 분리되었다[6]. 이는 과거영유아들의 외부놀이 가 중심이었다면 최근은 내부놀이가 주를 이루는 원인도 포함 될 것이라고 유추할 수 있다.

계절별로는 여름(28\%)과 겨울(28\%)이 다소 높게 나타났고 봄(24\%)과 가을(20\%)로 비슷하게 분리되었으나 Hyun 등의 계 절별 조사에서는 여름이 가장 높고 겨울, 가을, 봄이 비슷하게 분리되었다[6].

부위별로는 족부백선(51\%)로 가장 많았으며 다음 순으로는 몸백선(13\%), 조갑백선(11\%), 사타구니백선(8\%), 두부백선 (6\%), 수부백선(4\%), 그리고 얼굴백선(3\%)의 순으로 분리되는 반면 Jun 등의 조사에서는 족부백선(25.6\%)이 가장 많았고 사 타구니백선(20.9\%), 두부백선(17.9\%), 몸백선(14.3\%), 수부백 선(13.8\%), 조갑백선(7.5\%), 그리고 얼굴백선(0.1\%)으로 나타 났다. 과거와 비교시 족부백선은 증가추세를 보이며 다른 부위 는 약간의 차이를 나타냈다.

연령군에 따른 조사결과, 영유아기와 학령기, 그리고 사춘기 모두에서 족부백선이 가장 높고 몸백선, 조갑백선의 순서로 분 리되었으며 다음순서로는 영유아기와 학령기는 두부백선, 그 리고 수부백선으로 분포하였으나 사춘기에서는 사타구니백선, 수부백선 등으로 분리되었다. Jun 등의 조사에서는 영유아기와 학령기에서는 두부백선이 가장 높고 사춘기에서는 족부백선과 사타구니백선이 가장 높게 나타났다.

균종별 분포에서는 원인균종으로는 T. rubrum (21\%), M. canis (3\%), T. mentagrophytes (1\%)으로 분포하였으며 Hyun 등이 T. rubrum(53.7\%), M. canis(30.6\%), T. mentagrophytes (9.6\%)의 순으로 동정한 결과와 분리율에는 다소 차이가 있으 며 분리균종은 동일하게 나타났다. 소아의 부위별 분포가 높은 곳인족부백선과사타구니백선, 그리고 몸백선, 수부백선 및 조 갑백선의 원인균종이 T. rubrum이기에 소아백선의 주요 원인 균임을 설명하였다[6].

피부사상균 분리동정방법은 $\mathrm{KOH}$ 를 이용한 직접도말검사와 인공배지를 이용한 배양검사, lactophenol cotton blue로 염색 을 수행하여 형태학적 성상을 통해 동정하였다. 현재는 곰팡이 균주의 유전자 분석을 위한 데이터 베이스가 구축이 미비하여 향 후 원인균의 분리율을 높이기 위해서는 PCR기법을 통한 동정이 필요할 것으로 생각된다. 본 연구에서는 짧은 기간이지만 고도의 경제성장으로 생활환경, 신체지수의 변화가 무상한 시점에서의 
소아청소년을 대상으로 감염보고는 의의가 있다고 사료되며 이 는 지속적인 자료수집을 통해 향후 소아청소년의 발달단계에 따 른 피부진균학적 기초 자료로 유용할 것으로 사료된다.

\section{요 약}

2017년 1월 2일부터 12월 30일까지 내원한 검사환자 13,093 명 중 소아청소년환자는 691명이며 백선균 분리환자는 179명으 로 $25.9 \%$ 가 분리되었다. 분석 결과 전체 소아환자 691명 중 남성 은 423명으로 61\%이며 여성은 268명으로 39\%로 분포하였다. 연령군별 조사에서는 신체변화가 가장 많은 시기인 사춘기 (317, 46\%)에서 높게 나타났고 다음으로 학령기 $(203,29 \%)$ 와 영 유아기(171, 25\%)의 순서로 나타났다. 계절별 조사에서는 여름 $(195,28 \%)$ 과 겨울(191, 28\%)이 높게 분리되었고 봄(165, 24\%)과 가을(140, 20\%)의 순으로 분리되었다. 부위별로는 족부백선(353, $51 \%)$ 로 가장 많았으며 다음 순으로는 몸백선( $91,13 \%)$, 조갑백선 (77명, $11 \%)$, 사타구니백선(55, 8\%), 두부백선(39, $6 \%$ ), 수부백선 (29, $4 \%)$, 그리고 얼굴백선(22, 3\%)의 순으로 분리되었다. 연령별 에 따른 부위별 질환은 소아연령 모두에서 족부백선이 가장 많이 분 리되었고 다음 순으로는 유아기와 학령기에서는 몸백선, 조갑백선, 수부백선, 그리고 두부백선의 순으로 분리되었다. 사춘기에서는 몸 백선, 조갑백선, 그리고 사타구니백선으로 분리되었다. 원인균종은 Trichophyton rubrum이 가장 많이 분리되었다. 본 자료분석을 통 해 소아의 발달단계에 따른 백선의 분포와 분리균종을 확인하였으 며 향후 지속적인 자료수집을 통해 소아피부진균증의 분포 추이에 도움이 될 것으로 사료된다.

\section{Acknowledgements: None}

Conflict of interest: None

Author's information (Position): Kim SJ ${ }^{1}$, Professor; Bang $\mathrm{YJ}^{2}$, M.T.

\section{REFERENCES}

1. Lee YW, Yun SJ, Lee JB, Kim SJ, Lee SC, Won YH. Clinical and mycological studies on dermatomycosis (2001-2010). Korean J Med Mycol. 2013;18:30-38.

2. Moon HJ, Lee JB, Kim SJ, Lee SC, Won YH. Clinical and mycological studies on dermatomycosis (1991-2000). Korean J Med Mycol. 2002;7:78-85.

3. Seebacher C, Bouchara JP, Mignon B. Updates on the epidemiology of dermatophyte infections. Mycopathologia. 2008:166: 335-352.

4. Suh SB. Study of Korean dermatomycosis. Daegu Medical Paper. 1959; 2:1-33.

5. Won YH, Kim SH, Kim SH, KimYP. A clinical and mycological studies of dermatomycosis (1976-1985). Korean J Dermatol. 1987;25:753-760.

6. Hyun DN, Chung H, Park JS, Jun JB. A clinical and mycological study of dermatophytoses in children. Korean J Med Mycol. 2009;14:69-78.

7. Bang YJ, Lee GS, Kim SY. Isolation of Microsporum canis from Tinea capitis of during treatment with itraconazole. Korean J Clin Lab Sci. 2001;33:91-94.

8. Choi CP, Lee MH. Six cases of Tinea capitis in adults. Korean J Med Mycol. 2006;11:31-34.

9. Choi YW, Kwon OS, Park JS, Bang YJ. Microscopic findings of macroconidia in Microsporum canis. Korean J Med Mycol. 2017;22:84-85. https://doi.org/10.17966/KJMM.2017.22.2.84

10. Hwang SM, Kim DM, Suh MK, Ha GY, Kim JR. A case of psoriasiform Tinea corporis caused by Microsporum canis. Korean J Med Mycol. 2010;15:165-169.

11. Jang SH, Yun SJ, Lee JB, Kim SJ, Lee SC, Won YH. Clinical study of dermatophytosis caused by Microsporum canis. Korean J Med Mycol. 2014;19:39-44.

12. Kim HR, Kwon OS, Kwon HJ, Park JS, Park KD, Choi JS, et al. A case of multiple Tinea infections in an infant child after contact with a dog. Korean J Med Mycol. 2016;21:47-51.

13. Bang YJ, Kim SY. Epidemiologic investigation of onychomycosis and Tinea pedis in children. Korean J Clin Lab Sci. 2007; 39:91-95.

14. Kim SJ. Epidemiologic study of zoophilic dermatophytoses between 2010 and 2016. Korean J Clin Lab Sci. 2017;49:439-445. https://doi.org/10.15324/kjcls.2017.49.4.439.

15. Lee JH, Yu SY, Koo BK, Moon C. Study on imported case dimorphic fungi isolated from clinical specimen in Korea. Korean J Clin Lab Sci. 2018;50:29-36. https://doi.org/10.15324/kjcls. 2018.50.1.29.

16. Ahn HS. Pediatrics. 9th. Seoul: Daehan publishing; 2007. p15-21.

17. Kim SM, Lee YW, Ahn KJ. A clinical and mycological study of Tinea capitis. Korean J Med Mycol. 2006;11:184-190.

18. Michael GR. Dermatophytosis: Epidemiological and microbiological update. J Am Acad Dermatol. 2000;43;120-124.

19. Park JY, Shin DH, Choi JS, Kim KH. Isolation rates and carrier state of dermatophytes, nondermatophyte molds, Malassezia species, and Candida species in indoor dogs and cats in Daegu. Korean J Med Mycol. 2012;17:25-35.

20. Kim HJ, Jang HC, Lee SW, Chung H, Jun JB. A case of neonatal Tinea capitis. Korean J Med Mycol. 2006;11:195-198.

21. Kim SH, Suh MK, Kim JH, Ha GY, Kim JR. A case of kerion celsi caused by Microsporum canis probably transmitted from hamster. Korean J Med Mycol. 2009;14:23-27.

22. Kim SM, Park J, Lee JS, Cho YS, Yun SK, Kim HU. Two cases of Tinea capitis caused by Microsporum canis in elderly women. Korean J Med Mycol. 2010;15:18-21.

23. Park JS, Kim HG, Kwon DR, Kwon DG. Effects of low alternating current on growth of the Trichophyton tonsurans and Microsporum canis. J Mycol Infect. 2018;23:9-14. https://doi.org/10.17966/JMI.2018.23.1. 9.

24. Hsiao YH, Chen C, Han HS, Kano R. The first report of terbinafine resistance Microsporum canis from a cat. J Vet Med Sci. 2018;80:898-900. https://doi: 10.1292/jvms.17-0680. 